\title{
A neonate infected with coronavirus disease 2019 with severe symptoms suggestive of multisystem inflammatory syndrome in childhood
}

A 9-day-old male neonate with 39 weeks gestation was referred to the Emergency Department of Besat's Hospital in Hamadan City located in the west of Iran, with a history of fever and poor feeding. He was born with a delivery method of cesarean section, birth weight 3,300 g, and Apgar score of 8/9. There was no history of cough and rhinorrhea. The neonate's mother had no complications during pregnancy and delivery and they were discharged from the hospital one day after the delivery. The neonate's parents were asymptomatic, but the neonate's grandfather was infected with coronavirus disease 2019 (COVID-19). The neonate's grandfather was in contact with the neonate since birth. He was admitted to the hospital with the diagnosis of COVID-19 one day after neonate hospitalization. He was tachycardic and tachypneic. On the first day, oxygen with hood and $5 \mathrm{~L} / \mathrm{min}$ volume was administered and the neonate was transferred to the neonatal care unit (Table 1). Because of the COVID-19 pandemic, a nasopharyngeal swab was sent for reverse-transcription polymerase chain reaction (RT-PCR) assay to the laboratory. RT-PCR was done 10 days after birth and the result of PCR was positive. Also, cerebrospinal fluid (CSF) analysis and urine analysis were normal. In the chest computed tomography (CT) scan bilateral, peripheral ground glass infiltration and opacity were observed (Fig. 1). Antibiotics therapy (ampicillin $25 \mathrm{mg} / \mathrm{kg}$ every 6 hours plus cefotaxim $50 \mathrm{mg} / \mathrm{kg}$ every 8 hours) was started before the result of bacterial cultures of blood, urine, and CSF. The neonate was infected with COVID-19 and gastrointestinal symptoms such as vomiting, diarrhea, and severe respiratory distress. These completed the multisystem inflammatory syndrome in children (MIS-C) criteria (Table 1). According to the protocol of Iran in the field of treatment of COVID-19, the patient with a diagnosis of MIS-C was treated with intravenous immunoglobulin (IVIG).

\section{Multisystem inflammatory syndrome in neonates and COVID-19}

The evidence suggests that most infants were not infected with COVID-19 and if they were infected had very mild symptoms. ${ }^{1)}$ However, some neonates have a severe MIS-C which can involve several vital organs. MIS-C is a condition where different body parts can become inflamed, including the heart, lungs, kidneys, brain, skin, eyes, or gastrointestinal organs. Children with MIS-C may have a fever and various symptoms, including abdominal pain, vomiting, diarrhea, neck pain, rash, bloodshot eyes, or feeling extra tired. This new syndrome can be related to COVID-19.2,3) MIS-C is rare, but this disease may have been observed during the COVID-19 pandemic in some studies. ${ }^{3,4)}$ In the present case, the neonate was infected with COVID-19 and gastrointestinal symptoms such as vomiting, diarrhea, and severe respiratory distress.

\section{Difference between MIS-C and severe COVID infection in the neonate}

MIS-C often occurs in age $<21$ years with clinical criteria: A

Table 1. Neonate's symptoms of multisystem inflammatory syndrome in childhood and test results during hospitalization

\begin{tabular}{|c|c|c|}
\hline Variable & Results & Reference range \\
\hline Temperature ( ${ }^{\circ} \mathrm{C}$ ) & 38.3 & - \\
\hline blood pressure (mmHg) & $65 / 40$ & - \\
\hline Respiratory rate (/min) & 74 & - \\
\hline Heart rate (/min) & 160 & - \\
\hline $\mathrm{O}_{2}$ saturation (\%) & 88 & - \\
\hline Hemoglobin (g/dL) & 13.9 & $11.5-14.5$ \\
\hline White blood cell (cell/mm³) & 5,500 (low) & $9,000-30,000$ \\
\hline Neutrophil (\%) & 42 & $54-62$ \\
\hline Iymphocyte (\%) & 58 & $25-33$ \\
\hline Platelet (×10\%/L) & 184 & $150-400$ \\
\hline $\operatorname{ESR}(\mathrm{mm} / \mathrm{hr})$ & 23 (high) & $1-10$ \\
\hline C-reactive protein (mg/dL) & 12 (high) & $0-6$ \\
\hline Urine, blood, and CSF culture & No growth & No growth \\
\hline \multicolumn{3}{|l|}{ Presenting symptoms } \\
\hline Gastrointestinal symptom & Vomiting, diarrhea & - \\
\hline Respiratory symptom & $\begin{array}{c}\text { Tachypnea, severe } \\
\text { respiratory distress, } \\
\text { saturation with pulse } \\
\text { oximetry was } 88 \%\end{array}$ & - \\
\hline Fever & Positive, tachycardia & - \\
\hline
\end{tabular}

CSF, cerebrospinal fluid; ESR, erythrocyte sedimentation rate.

Corresponding author: Ensiyeh Jenabi, PhD, Autism Spectrum Disorders Research Center, Hamadan University of Medical Sciences, Hamadan, Iran Email: En.jenabi@yahoo.com, https://orcid.org/0000-0002-4536-0814

Received: 25 April, 2021, Revised: 13 August, 2021, Accepted: 14 August, 2021

This is an open-access article distributed under the terms of the Creative Commons Attribution Non-Commercial License (http://creativecommons.org/licenses/bync/4.0/) which permits unrestricted non-commercial use, distribution, and reproduction in any medium, provided the original work is properly cited.

Copyright (c) 2021 by The Korean Pediatric Society 


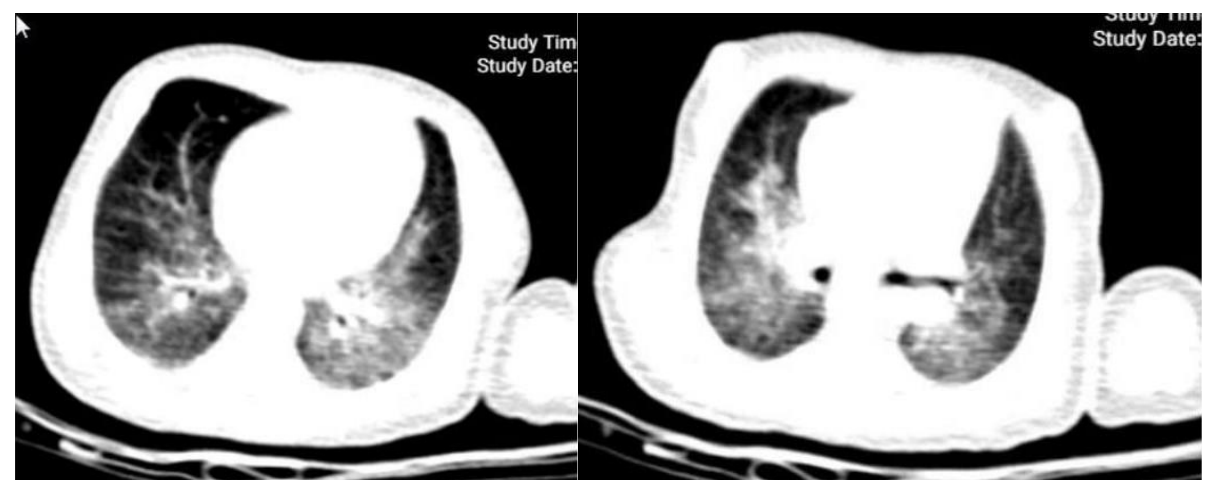

Fig. 1. Bilateral peripheral ground glass infiltration and opacity.

minimum 24-hour history of subjective or objective fever $\geq 38.0$ ${ }^{\circ} \mathrm{C}$ and severe illness necessitating hospitalization and 2 or more organ systems affected (i.e., cardiac, renal, respiratory, hematologic, gastrointestinal, dermatologic, neurological). Laboratory evidence of inflammation include 1 or more of the following: an elevated C-reactive protein (CRP), erythrocyte sedimentation rate, fibrinogen, procalcitonin, D-dimer, ferritin, lactate dehy. drogenase, or interleukin-6; elevated neutrophils or reduced lymphocytes and low albumin. ${ }^{5}$ ) The severe acute COVID-19 often occurs in children with an underlying health problem, MIS-C is found in less than 1\% of children with COVID-19, mostly with no previous disease. In MIS-C, at least 2 organ systems are affected (i.e., cardiac, renal, respiratory, hematologic, gastrointestinal, dermatologic, neurological), which does not only involve the heart. $\left.{ }^{6}\right)$

\section{Treatment of MIS-C in the neonate}

Some adjunct therapies have been used because of the profound inflammatory response and Kawasaki disease (KD)-like features, with IVIG. According to a Western New York guidelines ${ }^{7)}$ and our country approach, patients with KD-like illness or patients with COVID-19 diagnosis and in high-risk categories (infants, $\mathrm{KD}$ shock syndrome, $\mathrm{CRP}>130 \mathrm{~g} / \mathrm{dL}$, admission echo $z$ score $>2.5$ or aneurysms, Asian race) should receive IVIG 1-2 g/ $\mathrm{kg}$ as a single infusion with 3-day pulse methylprednisolone.

\section{Result of treatment}

At admission, the patient had a deceased $\mathrm{O}_{2}$ saturation (80\%) that by pulse oximetry reached $85 \%$ after receiving oxygen through the hood. Respiratory distress did not improve after 2 days of treatment with antibiotics. After the PCR test result, the neonate was treated with 1 dose IVIG $(1 \mathrm{~g} / \mathrm{kg})$. Two days after treatment with IVIG, oxygen saturation reached $95 \%$ and respiratory distress improved. The patient was discharged and during follow-up (2 weeks after discharge), the neonate was in good general condition.

The common symptoms in children with acute COVID-19 infection are fever and cough. Other symptoms may include sore throat, rhinorrhea, or congestion, myalgias, headache, fatigue, and gastrointestinal symptoms including nausea, vomiting, or diarrhea. Infants may also present with isolated fever, poor feeding, or fussiness. ${ }^{8)}$ A review study reported that mortality rates of MIS-C are lower compared to adult forms of severe COVID-19 disease. $^{9)}$

\section{Key message}

Question: Can multisystem inflammatory syndrome in childhood (MIS-C) occur in the neonate associated with coronavirus disease 2019 (COVID-19)?

Finding: A 9-day-old neonate infected with COVID-19 had fever, respiratory distress, and gastrointestinal symptoms suggestive of MIS-C. This neonate recovered after treatment with intravenous immunoglobulin (IVIG).

Meaning: IVIG successfully treated a rare case of a 9-day-old neonate with COVID-19 and severe symptoms suggestive of MIS-C.

Fatemeh Eghbalian, $\mathrm{MD}^{1}$, Ghazal Sami, $\mathrm{MD}^{1}$, Saeid Bashirian, $\mathrm{PhD}^{2}$, Ensiyeh Jenabi, $\mathrm{PhD}^{3}$

${ }^{1}$ Department of Pediatrics, Faculty of Medicine, Hamadan University of Medical Sciences, Hamadan, Iran

${ }^{2}$ Social Determinants of Health Research Center, Hamadan University of Medical Sciences, Hamadan, Iran

${ }^{3}$ Autism Spectrum Disorders Research Center, Hamadan University of Medical Sciences, Hamadan, Iran

\section{Footnotes}

Conflicts of interest: No potential conflict of interest relevant to this article was reported.

\section{References}

1. Eghbalian F, Esfahani AM, Jenabi E. COVID-19 virus in a 6-day-old girl neonate: a case report. Clin Pediatr 2020;59:1288-9.

2. De Rose DU, Piersigilli F, Ronchetti MP, Santisi A, Bersani I, Dotta A, et al. 
Novel Coronavirus disease (COVID-19) in newborns and infants: what we know so far. Ital J Pediatr 2020;46:1-8.

3. Dong Y, Mo X, Hu Y, Qi X, Jiang F, Jiang Z, Tong S. Epidemiology of COVID-19 Among Children in China. Pediatrics. 2020;145:e20200702.

4. Coronado Munoz A, Nawaratne U, McMann D, Ellsworth M, Meliones J, Boukas K. Late-onset neonatal sepsis in a patient with Covid-19. N Engl J Med 2020;382:e49.

5. Bhat CS, Gupta L, Balasubramanian S, Singh S, Ramanan AV. Hyperinflammatory syndrome in children associated with COVID-19: need for awareness. Indian Pediatr 2020;57:929-35.

6. Nakra NA, Blumberg DA, Herrera-Guerra A, Lakshminrusimha S. Multisystem inflammatory syndrome in children (MIS-C) following SARSCoV-2 infection: review of clinical presentation, hypothetical pathogenesis, and proposed management. Children 2020;7:69:1-14.

7. Hennon TR, Penque MD, Abdul-Aziz R, Alibrahim OS, McGreevy MB, Prout AJ, et al. COVID-19 associated multisystem inflammatory syndrome in children (MIS-C) guidelines: a Western New York approach. Prog Pediatr Cardiol 2020;23:101232.

8. Mithal LB, Machut KZ, Muller WJ, Kociolek LK. SARS-CoV-2 infection in infants less than 90 days old. J Pediatr 2020;224:150-2.

9. Kabeerdoss J, Pilania RK, Karkhele R, Kumar TS, Danda D, Singh S. Severe COVID-19, multisystem inflammatory syndrome in children, and Kawasaki disease: immunological mechanisms, clinical manifestations and management. Rheumatol Int 2021;41:19-32.

How to cite this article: Eghbalian F, Sami G, Bashirian S, Jenabi E. A neonate infected with coronavirus disease 2019 with severe symptoms suggestive of multisystem inflammatory syndrome in childhood. Clin Exp Pediatr 2021;64:596-8. https://doi.org/10.3345/cep.2021.00549 